\title{
Impacto do Plano Simplificado de Previdência Social sobre as Contribuições Voluntárias ao Sistema de Previdência *
}

\author{
Miguel N. Foguel \\ Pesquisador - Instituto de Pesquisa Econômica Aplicada (IPEA) \\ Endereço para contato: Av. Presidente Antonio Carlos, 51 - $14^{\circ}$ andar - Centro, Rio de Janeiro - RJ \\ CEP: 22020-010 - E-mail: miguel.foguel@ipea.gov.br
}

\author{
Ajax Moreira \\ Pesquisador - Instituto de Pesquisa Econômica Aplicada (IPEA) \\ Endereço para contato: Av. Presidente Antonio Carlos, 51 - $17^{\circ}$ andar - Centro, Rio de Janeiro - RJ \\ CEP: 22020-010 - E-mail: ajaxmoreira@gmail.com

\section{Daniel Santos} \\ Professor - Faculdade de Economia, Administração e Contabilidade de Ribeirão Preto (FEA-RP/USP) \\ Endereço para contato: Av. Bandeirantes, 3900 - Monte Alegre - Ribeirão Preto - SP \\ CEP: 14040-905 - Email: daniel.ddsantos@gmail.com
}

Recebido em 17 de abril de 2012. Aceito em 20 de agosto de 2012.

\section{Resumo}

Em abril de 2007, com o objetivo de estimular a inserção previdenciária no Brasil, o governo federal apresentou um plano de previdência alternativo para os contribuintes individuais, o Plano Simplificado de Previdência Social (PSPS). Restringindo os optantes a requerem aposentadoria somente pelo critério de idade, o PSPS permite uma redução da alíquota de contribuição de $20 \%$ para $11 \%$ para os trabalhadores que contribuem voluntariamente sobre um salário mínimo. O principal objetivo deste estudo foi verificar se o PSPS teve algum impacto sobre a probabilidade de os trabalhadores não formais contribuírem para a Previdência Social. Para tanto, utilizou-se uma amostra aleatória do Cadastro Nacional de Informações Sociais (CNIS), uma base de dados administrativa que contém informações sobre a história previdenciária dos trabalhadores. O método empregado para estimar o impacto do PSPS foi o amplamente conhecido método das diferenças-em-diferenças. Os resultados mostram que o PSPS parece ter aumentado a probabilidade de os trabalhadores que contribuem em torno de um salário mínimo realizarem contribuição voluntária à Previdência.

\section{Palavras-Chave}

previdência social, autônomos, avaliação de impacto

- Gostaríamos de agradecer os comentários de Carlos Henrique Corseuil, Ronaldo Seroa, Lauro Ramos, Danilo Coelho, Paulo Levy, Marco Antonio Cavalcanti e Maurício Reis. Todos os erros remanescentes são de responsabilidade dos autores. 


\begin{abstract}
In April 2007 aiming at increasing participation of self-employed workers in the public pension system the Brazilian government launched the Plano Simplificado de Previdência Social (PSPS) - Simplified Pension Plan. The plan allows a reduction of the contributory percentage from $20 \%$ to $11 \%$ for any self-employed worker who decided to contribute exactly on the value of the minimum wage. Those who opt for the plan can only retire through the age criterion. The main goal of this paper was to verify whether the PSPS had an impact on the probability of voluntary contribution to the social security system of non-formal workers. To reach that goal, we use a random sample extracted from the Cadastro Nacional de Informações Sociais (CNIS) - Social Information National Register , an administrative database that contains information on the history of social security contributions of all workers. The method employed to estimate the impact was the well-known difference-in-differences approach. The results show that the PSPS seems to have increased the probability of voluntary contribution of workers whose base of contribution is the minimum wage.
\end{abstract}

\title{
Keywords
}

pension system, self-employed, program evaluation

\author{
JEL Classification \\ C23, C25, D04, E62
}

\section{Introdução}

O Brasil possui um sistema previdenciário contributivo de repartição que garante o pagamento de benefícios futuros de aposentadoria a qualquer trabalhador que tenha cumprido as regras de contribuição previdenciária. ' Além desse fluxo de pagamentos futuros de aposentadoria (ou pensão, no caso de morte do trabalhador), o sistema também oferece um conjunto de benefícios correntes que inclui auxílio-doença e invalidez, assim como o salário-maternidade. A contribuição para o sistema pode ser compulsória, quando o indivíduo está empregado no setor formal (trabalhadores com carteira assinada e servidores públicos), ou voluntária (trabalhadores autônomos, sem carteira assinada e empregadores). ${ }^{2}$

1 No sistema de repartição ocorrem transferências entre gerações, ou seja, o fluxo de pagamentos de aposentadoria é financiado pelas contribuições dos trabalhadores atuais. Naturalmente, o sistema de repartição está sujeito a desbalanços entre os pagamentos de benefícios e contribuições previdenciárias. Esses déficits são cobertos pelo Tesouro Nacional.

2 O sistema previdenciário brasileiro é subdividido em dois grandes regimes: o Regime Geral de Previdência (RGPS), que engloba os trabalhadores que estão no setor privado (incluindo os contribuintes voluntários), e o Regime Próprio de Previdência Social (RPPS), que atende os empregados públicos de cada ente federativo (União, estados, DF e municípios). 
No período recente, o equilíbrio do sistema previdenciário vem sendo discutido tanto pelo lado dos gastos quanto pelo da arrecadação. O envelhecimento populacional, o aumento do tempo médio de vida, a concessão de benefícios previdenciários a parcelas da população que não contribuíram para o sistema e a concentração dos benefícios em cima de um salário mínimo real crescente são alguns dos principais fatores que explicam a expansão dos gastos previdenciários nas últimas décadas. Pelo lado da arrecadação, a evasão fiscal resultante da dificuldade de cobrar tributos sobre rendimentos de trabalhadores sem contrato formal de trabalho é um dos principais problemas enfrentados pelo sistema. Sem dúvida, além dos impactos causados pelas mudanças demográficas e institucionais, a dimensão da informalidade laboral é uma das mais importantes para explicar a evolução do sistema previdenciário brasileiro. ${ }^{3}$ Ao estudar os impactos de um plano de previdência voltado para os trabalhadores autônomos, este artigo procura contribuir para um melhor entendimento dos efeitos da informalidade sobre o sistema de previdência brasileiro. ${ }^{4}$

Além do argumento fiscal, a inclusão de trabalhadores informais no sistema previdenciário contribui para que este atinja seu propósito de oferecer uma rede de proteção social aos trabalhadores, visto que no Brasil os benefícios previdenciários são concebidos para serem mais do que uma forma de poupança das famílias. Ao ingressar no sistema, os indivíduos passam a contar com amplo leque de possíveis benefícios associados às mais diversas contingências, tais como acidentes de trabalho e morte do cônjuge. ${ }^{5}$ Se ainda considerarmos que os trabalhadores alocados no setor informal possuem renda relativamente baixa e estão especialmente sujeitos a tais contingências,

3 Apesar de ter havido uma queda da informalidade no mercado de trabalho brasileiro, a proporção de trabalhadores formais (com carteira e funcionários públicos) era ainda de $44 \%$ do total de ocupados em 2008. Em termos de contribuição à previdência, embora tenha ocorrido uma elevação de 3 pontos de percentagem na parcela dos trabalhadores que contribui entre 2001 e 2006, o nível ainda era de 55\% neste último ano. Esses números foram calculados com base nos microdados da PNAD/IBGE.

4 Vale notar que não houve um aumento significativo da parcela dos trabalhadores autônomos contribuintes da previdência antes do lançamento do plano de previdência a ser avaliado neste artigo. De fato, utilizando os microdados da PNAD/IBGE entre 2001 e 2006, a proporção de trabalhadores por conta própria que contribuíam para previdência só aumentou em 1 ponto de percentagem, passando de $14,8 \%$ para $15,8 \%$.

5 Note-se que, além de pagar benefícios programáveis de aposentadoria e pensão aos idosos, o sistema previdenciário brasileiro tem uma dimensão assistencial - por exemplo, através do pagamento do Benefício de Prestação Continuada (BPC/LOAS) - e funciona também como um seguro para uma série de contingencias tais como acidentes de trabalho e invalidez. Nesse sentido, os benefícios previdenciários são mais do que uma forma de poupança dos trabalhadores. 
é razoável supor que estariam dentre os que mais precisam de uma rede de proteção como a Previdência.

Além da introdução de mudanças de regras do sistema previdenciário nas últimas décadas (por exemplo, o fator previdenciário e alteração da idade mínima de aposentadoria para os servidores públicos), os gestores do sistema vêm fazendo um esforço para atrair trabalhadores informais que hoje não contribuem. Dentre as iniciativas recentes, podemos destacar a criação do Plano Simplificado de Previdência Social (PSPS) em abril de 2007, que reduziu a alíquota de contribuição de $20 \%$ para $11 \%$ para os trabalhadores que contribuem voluntariamente sobre o valor de um salário mínimo. Os trabalhadores que decidam aderir ao PSPS passam (continuam) a fazer jus ao pacote de auxílios previdenciários (e.g. auxílio-doença e salário-maternidade), porém só podem se aposentar pelo critério de idade, ou seja, exclui-se a possibilidade de o trabalhador optante requerer aposentadoria por tempo de contribuição. ${ }^{6}$

O Gráfico 1 apresenta a evolução do total de contribuintes individuais e do número de trabalhadores que aderiram ao PSPS. Os números do gráfico representam a diferença de cada série em relação a seu respectivo valor em abril de 2007. ${ }^{7}$ Como se pode ver, o número de trabalhadores que aderiram ao PSPS vem aumentado desde a sua introdução, principalmente nos primeiros dois anos após sua implementação. ${ }^{8}$ Todavia, não se pode afirmar com certeza se essas adesões resultaram da inserção de novos contribuintes individuais ou somente da migração do plano de previdência convencional para o PSPS. No entanto, o próprio Gráfico 1 fornece alguma evidência de que o PSPS pode ter promovido a inserção previdenciária, tendo em vista que o número de contribuintes voluntários aumentou. De fato, após abril de 2007, este número cresceu em comparação com o mes-

6 Podem solicitar aposentadoria por idade trabalhadores urbanos do sexo masculino a partir dos 65 anos e do sexo feminino a partir dos 60 anos. Os trabalhadores rurais, por sua vez, podem requerer aposentadoria por idade com cinco anos a menos: a partir dos 60 anos, homens, e a partir dos 55 anos, mulheres. O trabalhador também poderá solicitar aposentadoria por tempo de contribuição integral ou propocional. Para ter direito à aposentadoria integral, o trabalhador homem deve comprovar pelo menos 35 anos de contribuição e a trabalhadora mulher, 30 anos. Para se requerer a aposentadoria proporcional, é necessária a combinação de dois requisitos: tempo de contribuição e idade mínima.

7 No mês de lançamento do PSPS, 5.533 trabalhadores aderiram ao programa. Nesse mês, o número de CIs era de 3.892 .481 trabalhadores.

8 Em termos de médias mensais, entre abril de 2007 e março de 2008, cerca de 60 mil trabalhadores por mês aderiram ao PSPS; entre abril de 2008 e março de 2009, as adesões foram de 32 mil mensais; e entre abril e agosto de 2009 a média mensal foi de 8 mil trabalhadores. 
mo período do ano anterior: a taxa de crescimento de contribuintes individuais foi de $-2,1 \%$ entre abril de 2006 e março de 2007, e de 6,9\% entre abril de 2007 e março de 2008.

O objetivo deste artigo é estimar o impacto do PSPS sobre a probabilidade de que indivíduos excluídos do setor formal da economia contribuam para o sistema. Para tanto, faremos uso de microdados do Cadastro Nacional de Informações Sociais (CNIS), a única base que contém o histórico contributivo (e de pagamento de benefícios) de todos os indivíduos que em algum momento passaram pelo sistema previdenciário brasileiro. Tanto quanto sabemos, este é o primeiro artigo que faz uso dos microdados do CNIS para avaliar um programa previdenciário. Em termos metodológicos, empregaremos o método de diferenças-em-diferenças, o qual é baseado na escolha adequada dos grupos de tratamento e controle e demanda informações para os períodos anterior e posterior à introdução do programa.

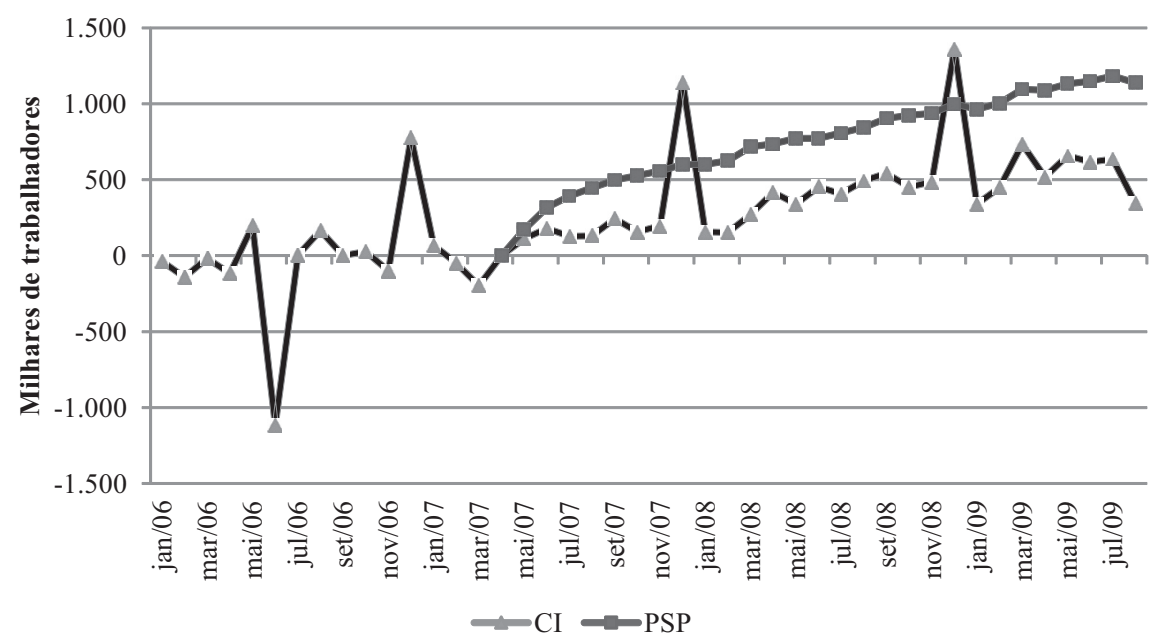

Gráfico 1 - Evolução do total de contribuintes individuais (CI) e de trabalhadores que aderiram ao PSPS - Diferença em relação a abril/2007

Fonte: DATAPREV.

Além desta introdução, o texto se divide em mais cinco seções. A próxima seção contém um sumário sobre a relação entre trabalho informal e os sistemas de previdência de alguns dos mais importantes países da América Latina. Na terceira seção é apresentada a descrição da base de dados utilizada na análise, e, na quarta seção, 
descreve-se a metodologia empregada no trabalho. Na quinta seção, apresentam-se os resultados das estimativas do impacto do PSPS sobre a probabilidade de contribuição autônoma à previdência. Por último, a seção 6 apresenta uma síntese dos principais resultados do trabalho.

\section{Sistemas Previdenciários e Trabalhadores Informais na Amé- rica Latina}

Desde a implementação dos primeiros sistemas de seguridade social na Alemanha do século XIX, existe a preocupação dos gestores públicos de garantir que toda a população tenha acesso a benefícios mínimos em caso de contingências adversas. Os primeiros sistemas, ditos Bismarkianos (ou PAYG - Pay as You Go), tipicamente vinculavam o acesso aos benefícios a contribuições periódicas dos trabalhadores formalmente contratados, e buscavam assegurar os indivíduos contra a perda da capacidade produtiva e geração de renda individual ou familiar. As contribuições são remetidas a um fundo comum e o risco é desse modo compartilhado entre seus membros.

Devido à elevada participação da economia informal no emprego e produto na América Latina, a inclusão dos trabalhadores desse setor no sistema de seguridade tornou-se uma preocupação dos gestores públicos. Na grande maioria dos países, contudo, a modalidade típica de ocupação informal é o trabalho por conta própria, em que as flutuações de renda devidas a choques exógenos se confundem com riscos voluntariamente tomados no exercício da atividade. Para estes trabalhadores, a solução mais comum foi a construção de um fundo específico, com regras mais flexíveis e menor amplitude de contingências asseguradas. Além disso, em muitos casos, os recursos advindos das contribuições dos trabalhadores iam parcial ou totalmente para contas individuais de poupança previdenciária ao invés de um fundo mútuo. Nestes casos, não é claro se o não pagamento de contribuições em determinado mês é um problema relevante para investigação. Do ponto de vista da cobertura previdenciária, os trabalhadores permanecem cobertos desde que futuramente reembolsem as contribuições mensais faltantes. Do ponto de vista do financiamento do sistema, os equilíbrios orçamentários dos fundos específicos para contribuintes independentes e contas individuais seguem regras específicas que podem ser elaboradas de modo a equacionar 
eventuais faltas contributivas. Nesse sentido, o Brasil constitui um dos poucos casos em que todos os trabalhadores devem contribuir mensal e obrigatoriamente para um mesmo fundo que os demais trabalhadores, e para o qual a pergunta central deste artigo é particularmente relevante. $^{9}$

Apesar disso, existem em diversos países programas que visam à inclusão de trabalhadores por conta própria no sistema de seguridade. Esses programas podem ser divididos entre os contributivos, isto é, cujo acesso aos benefícios depende do pagamento de contribuições, e os não contributivos (ou assistencialistas), geralmente destinados a indivíduos pobres. O programa mais comum de estímulo à contribuição previdenciária para este público na América Latina é o Monotributo, iniciado na Argentina e adaptado no Uruguai e Venezuela. Neste programa, os trabalhadores por conta própria pagam um imposto único com alíquota reduzida que substitui impostos de renda e contribuição previdenciária, bem como impostos incidentes sobre a pessoa jurídica associada ao empreendimento em questão. Em certo sentido, o Monotributo se assemelha a uma combinação do PSPS com o programa Simples brasileiro.

Uma das racionalidades para a redução de alíquotas de contribuição para os trabalhadores mais pobres é baseada em imperfeições no mercado de crédito. A esse respeito, analisando apenas os trabalhadores de baixa renda, Neri (1998, apud Neri et al., 2007) argumenta que, devido ao difícil acesso dos microempresários ao crédito, a contribuição previdenciária pode ser considerada um artigo de luxo, dado que existiria um alto custo de oportunidade para esses indivíduos pouparem.

Reduções na alíquota de contribuição e/ou aumento de benefícios para trabalhadores por conta própria vêm sendo ainda experimentados em diversos países dentro e fora da América Latina, tais como China (redução de 28\% para 20\% dos ganhos), África do Sul (dedução fiscal para contribuições feitas a planos oferecidos por companhias de seguro), Bangladesh (concessão de microcrédito a juros

9 Em países como Argentina e Uruguai (e o Chile, em processo de transição), os autônomos são obrigados a participar de algum fundo previdenciário, dos diversos disponíveis segundo a categoria em que se enquadre. Na Colômbia, o fundo é único, mas os trabalhadores informais podem optar por não contribuir para o pacote completo de benefícios. Outros países como a Bolívia, El Salvador, Guatemala, México, Panamá, Nicarágua e Peru permitem que o trabalhador escolha se quer ou não contribuir. 
subsidiados com contrapartida de depósito em poupança previdenciária), Quênia (regime flexível de contribuições com facilitação de pagamento através de telefonia celular), e Costa Rica (participação em regime progressivo do Estado na contribuição previdenciária de trabalhadores pobres).

Outro grupo de trabalhadores que são comumente considerados informais no Brasil é formado por empregados sem contrato formal de trabalho. A visão predominante na América Latina é a de que uma vez que o indivíduo é assalariado, a existência de trabalhadores sem contrato se deve ao racionamento existente nas vagas oferecidas por firmas que optam por formalizar seus empregados. A inclusão desses trabalhadores no sistema de seguridade ficaria assim fortemente associada ao estímulo que firmas que hoje contratem informalmente deixem de fazê-lo. ${ }^{10}$

A literatura a respeito do impacto de intervenções na economia informal sobre a cobertura previdenciária e/ou da seguridade social é relativamente escassa. Alguns dos trabalhos existentes sugerem que os programas de simplificação tributária são atraentes: segundo Bertranou (2007), dois terços dos trabalhadores argentinos independentes que contribuem para a previdência o fazem através do plano simplificado (Monotributo). Lanzilotta (2009) mostra que no caso uruguaio o número de inscritos no programa Monotributo quintuplicou entre 2003 e 2008, acelerando fortemente o processo de adesão após reforma tributária em 2007, que reduziu alíquotas e facilitou o processo de afiliação (a autora estima que 170 mil dos 300 mil trabalhadores por conta própria acabarão por potencialmente aderir ao programa). No caso de Costa Rica, Valverde (2009) mostra que a contribuição compartilhada de trabalhadores informais e do Estado elevou a taxa de afiliação dos trabalhadores por conta própria ao sistema previdenciário. Nesse regime, o Estado arca com parte da carga contributiva, sendo que esta parte decai com a renda do trabalhador.

No caso brasileiro, Delgado et al. (2007) fazem uma avaliação abrangente do efeito da lei do Simples de 1996 - que simplifica a declaração e reduz a contribuição previdenciária - sobre a formalização do mercado de trabalho. Mostra-se que, apesar da estagnação econômica ocorrida no período 2000-2005, houve um crescimento acentuado

${ }^{10}$ Maloney (1999) e Bosh e Maloney (2005) questionam esse paradigma, mostrando que também há escolha voluntária de trabalhadores por ocupações em setores informais. 
do emprego nas empresas optantes pelo programa. O artigo, no entanto, não utiliza um instrumental estatístico que permita atribuir ao Simples a alteração causadora desta expansão.

Não obstante, há um conjunto de autores preocupados com possíveis efeitos adversos de risco moral associados ao sistema de seguridade e a seus programas. $\mathrm{O}$ acesso universal a diversos tipos de seguro reduz os incentivos para que os indivíduos trabalhem e formem poupança precaucional contra esses tipos de risco, reduzindo a capacidade de financiamento do próprio sistema de seguridade. ${ }^{11}$

Tentativas de promover o acesso facilitado a um conjunto de serviços nos moldes do PSPS estimulam a poupança e contribuição de um grupo de trabalhadores que nada pagava e tinha acesso apenas parcial ao sistema de seguridade, para ajudar a financiá-lo. Os benefícios, no entanto, não são óbvios. A introdução desses mecanismos estimula potencialmente a informalização da economia, uma vez que, ceteris paribus, trabalhadores informais têm acesso aos mesmos benefícios dos formalizados, porém a um custo menor. De fato, é nesta direção que parte dos pesquisadores dedicados a avaliar o impacto de programas desse tipo rumou. Levy (2006), por exemplo, conclui que em países com muitos programas de seguridade, a escolha ocupacional dos agentes é afetada, eventualmente alocando-os em postos de baixa produtividade. Bosch e Tornel (2011) avaliam o programa mexicano Seguro Popular (que estendia o acesso a serviços de saúde a trabalhadores semiformais, isto é, que participavam apenas parcialmente do sistema de seguridade) e concluem que um aumento de $10 \%$ na exposição ao programa reduz as chances de que um trabalhador jovem seja formal em cerca de $2 \%$.

\footnotetext{
${ }^{11}$ Há outros argumentos contra os programas de seguridade social para trabalhadores informais, particularmente os por conta própria. Entre eles destacam-se três: o primeiro é que a informalidade é vista por muitos como um fenômeno passageiro ou sazonal, e sistemas de monitoramento de contribuições são particularmente caros, não justificando sua criação; o segundo é que não é óbvio se os motivos que justificam o compartilhamento de risco nos sistemas previdenciários se estendem aos trabalhadores por conta própria: grande parte das eventualidades contra as quais se deseja assegurar o trabalhador diz respeito ao vínculo trabalhista com a firma e sua continuidade (ver Binet e Kulke (2006)); o terceiro motivo é que os seguros contra contingências não trabalhistas passaram a ser universais em grande parte dos casos, sem que haja contribuição ou tributo especificamente vinculado (é o caso do sistema público de saúde e dos programas antipobreza no Brasil).
} 


\section{Base de Dados}

O CNIS é um arquivo administrativo que reúne dados oriundos de um conjunto amplo de fontes de informação do governo federal, que incluem as próprias informações previdenciárias (e.g., Guia de Recolhimento do FGTS e Informações à Previdência Social - GFIP, e Guia da Previdência Social - GPS), a Relação Anual de Informações Sociais (RAIS), o Cadastro Geral de Empregados e Desempregados (CAGED) e o Sistema de Controle de Óbitos (SISOBI)). Sua principal função é permitir aos gestores previdenciários reconstruir o histórico de contribuições e outras informações necessárias para determinar os direitos dos indivíduos aos benefícios oferecidos pelo sistema previdenciário (aposentadorias, pensões e benefícios temporários associados a condições de saúde, maternidade, etc.).

No CNIS constavam, em setembro de 2009, informações de 173 milhões de brasileiros vivos ou mortos, que representam o conjunto de pessoas com algum registro no sistema de previdência. ${ }^{12}$ Desse universo, foi extraída uma amostra aleatória de 200 mil indivíduos, que servirá de base para as estimativas do impacto do PSPS obtidas neste estudo. Além dos respectivos históricos contributivos (valor da contribuição, posição na ocupação a partir da qual a contribuição foi realizada, etc.), o banco de dados contém informações sobre sexo, data de nascimento, educação, localização geográfica referente a cada contribuição, dentre outras informações socioeconômicas dos indivíduos. No entanto, como revela a Tabela 1, as informações cadastrais dos contribuintes são omitidas (missing) para a maioria das variáveis. De fato, como mostra a primeira coluna da tabela, apenas o sexo e a data de nascimento estão declarados para a maioria dos registros. As demais informações, das quais se apresenta apenas uma seleção, não são utilizáveis. Como se pode ver pela segunda coluna, essas constatações praticamente não se alteram se considerarmos apenas os tributos dos contribuintes individuais que não foram realizadas de forma avulsa. ${ }^{13}$ Coerente com a finalidade do cadastro, as informações relativas à contribuição - tipo, data e valor - estão declaradas para a maioria de registros.

${ }^{12}$ Como veremos, é possível que haja registros duplicados e, portanto, que as 173 milhões de entradas representem na verdade um universo menor de indivíduos.

${ }^{13}$ Trabalhador que presta serviço a várias empresas, mas é contratado por sindicatos e órgãos gestores de mão de obra. Nesta categoria estão os trabalhadores em portos: estivador, carregador, amarrador de embarcações, quem faz limpeza e conservação de embarcações e vigia. Na indústria de extração de sal e no ensacamento de cacau e café também há trabalhador avulso. 
O sistema trabalhista-previdenciário brasileiro historicamente permite que trabalhadores possuam mais de um número de inscrição previdenciária (tipicamente o PIS - Programa de Integração Social), fato em geral motivado pela troca de emprego ou reingresso ao mercado de trabalho após período de inatividade. A existência de mais de uma inscrição referente ao mesmo indivíduo pode aumentar artificialmente o universo de contribuintes no Cadastro, se a dupla contagem não for corrigida. O Ministério da Previdência Social (MPS) e a empresa responsável pelo processamento de dados, DATAPREV, vêm ao longo do tempo empenhando intenso esforço para reduzir a incidência de dupla contagem no Cadastro, quer pela adoção de medidas administrativas que facilitem a utilização do número de inscrição inicialmente utilizado pelos trabalhadores nos diversos empregos que eventualmente tiveram em suas vidas, quer pelo desenvolvimento de algoritmos especializados em rastrear os diversos registros de um mesmo indivíduo existentes no sistema e associá-los a um único número de inscrição principal. Estas medidas vêm sendo aprimoradas ao longo do tempo, e espera-se que a incidência de dupla contagem tenha consequentemente diminuído com o passar dos anos. ${ }^{14}$ No CNIS, a variável que procura identificar um trabalhador é o Número de Identificação do Trabalhador (NIT), produzido a partir de um algoritmo que busca unificar informações de um mesmo indivíduo que entraram no Cadastro através de diferentes números identificadores (tais como o PIS).

Tabela 1 - Proporção das contribuições com dados inválidos por variável - Em \%

\begin{tabular}{lcc}
\hline Variável & Todas & Não avulsas \\
\hline Unidade da Federação & 40 & 25 \\
Grau de instrução & 50 & 37 \\
Data de início do vínculo & 0 & 0 \\
Data de fim do vínculo & 40 & 0 \\
Sexo & 7 & 7 \\
Data de nascimento & 7 & 7 \\
Contribuição (tipo, data, valor) & 2 & 2 \\
\hline
\end{tabular}

Fonte: Tabela construída com base na amostra do CNIS.

Notas: A tabela mostra, nas linhas, variáveis cadastrais do contribuinte e a caracterização da contribuição, e nas colunas as proporções medidas para o conjunto de todas as contribuições e para o subconjunto das contribuições que não são feitas de forma avulsa pelo contribuinteindividual.

${ }^{14}$ A falta de abrangência das informações previdenciárias/trabalhistas no Brasil no passado fez com que a cobertura do CNIS fosse relativamente baixa até meados da década de 1990. No entanto, a qualidade das informações sobre contribuições vem melhorando ao longo do tempo, em particular a partir da introdução da GFIP em 1999. 
Um segundo problema potencialmente importante nos dados do CNIS é a subnotificação de óbitos. As informações existentes no CNIS são abastecidas pelas constantes das guias de recolhimento preenchidas por trabalhadores e firmas no instante em que contribuições são realizadas, assim como por cadastros e formulários preenchidos no ato do recebimento de benefícios. Por construção, fica claro que, em períodos em que os indivíduos por algum motivo não efetuem contribuições ou recebam proventos, nenhuma informação nova é providenciada. Se nosso intuito for o de reconstruir a vida contributiva dos agentes, algum tipo de tratamento precisa ser dado para estes períodos. Para tanto, é fundamental saber se o indivíduo está vivo em um período em que não haja novos registros. Informações de óbitos no CNIS só são incluídas após estes serem checados em mais de uma fonte (para evitar que pessoas ainda vivas e com direitos previdenciários pendentes sejam dadas como mortas), o que muitas vezes resulta na omissão do óbito da base. Nesses casos, um morto pode ser tomado como um vivo que não contribui para $o$ sistema, sobre-estimando o número de vivos no CNIS. ${ }^{15}$

Resumindo, a PNAD é uma amostra representativa da população brasileira tomada no mês de setembro de cada ano, em que o indivíduo amostrado não é acompanhado ao longo dos anos e, portanto, não é possível construir o seu histórico. O CNIS é um registro administrativo de todos os contribuintes da previdência social, do qual retiramos uma amostra com o histórico de cada contribuinte que é identificado com o NIT. As características do CNIS fazem com que os indivíduos:

1) sejam subenumerados, já que desconsidera aqueles que nunca contribuíram para a previdência;

2) sejam sobre-enumerados, pois um indivíduo pode ter mais do que um NIT devido à falha no algoritmo de identificação dos indivíduos.

A fim de reduzir eventuais problemas de sobre-enumeração de pessoas no CNIS, a Tabela 2, assim como toda análise deste artigo,

${ }^{15}$ Esses problemas não são exclusivos do CNIS. Rofman e Lucchetti (2009) apontam que diversos bancos de dados latino-americanos provenientes de registros administrativos apresentam duplicações de registros e sub-reportagem de mortos. Esses autores também ressaltam a escassez de variáveis socioeconômicas nessas bases de dados. Bertranou (2007) reforça esse ponto mostrando que em alguns países como Argentina e Uruguai os registros previdenciários são fragmentados, e no Chile o banco de dados não é unificado. 
restringem-se aos NITs que tiveram algum registro de contribuição após o ano 2000. Isso se deve ao fato de que a qualidade das informações do CNIS passa a ser melhor a partir do início da década de 2000 com a introdução da GFIP. Uma das implicações desse critério é excluir da amostra todos os indivíduos aposentados antes de 2000 que não têm registro de contribuição utilizando a GFIP.

A Tabela 2 apresenta uma comparação do CNIS com a Pesquisa Nacional por Amostra de Domicílios (PNAD), que foi utilizada como referência tanto para a população brasileira quanto para o número de contribuições realizadas à previdência. ${ }^{16} \mathrm{~A}$ tabela está apresentada por coorte decenal de nascimento e para os anos correspondentes ao período de análise deste estudo (2006 a 2008).

Como mostra a Tabela 2, a contagem de pessoas pelo CNIS é menor que a da PNAD, com a razão do número de pessoas entre as bases girando entre 0,62 e 0,70 para as coortes mais nova e mais velha e entre 0,77 e 0,87 para as coortes intermediárias. Essa menor população pelo CNIS reflete em parte a opção de não contar os aposentados antes de 2000 no CNIS e em parte o fato de que nem todas as pessoas da população passaram pelo sistema previdenciário. Embora o CNIS apresente problemas de contagem de pessoas, o mesmo não parece ocorrer no que diz respeito ao número de contribuições previdenciárias. De fato, como mostra a Tabela 2, a razão entre a média anual de contribuições registradas no CNIS e as contribuições reportadas pela PNAD em setembro de cada ano gira em torno da unidade para todas as coortes de nascimento e anos analisados.

A fim de minimizar os problemas de enumeração do CNIS na avaliação do impacto do PSPS, utilizamos informações dos contribuintes do CNIS somente para período entre abril de 2005 e março de 2009, ou seja, 24 meses antes e 24 meses após a criação do PSPS. Como a janela temporal é de apenas quatro anos, admitimos que o intervalo de análise é suficientemente curto para que a probabilidade de um trabalhador ter mais de um NIT seja suficientemente pequena. Sob essa hipótese, definimos como ativo todo trabalhador entre 15 e 70 anos de idade que tenha tido pelo menos uma contribuição no intervalo de análise.

${ }^{16}$ A expansão da amostra da PNAD foi realizada com os pesos (atualizados) fornecidos pelo IBGE. A amostra do CNIS foi expandida utilizando-se o inverso do fator de amostragem. 
Para reconstruir a situação previdenciária dos trabalhadores de nossa amostra, o histórico do trabalhador foi completado incluindo-se registros para os NITs de trabalhadores ativos para todos os meses do período em estudo nos quais o NIT não tem registro de contribuição. Estamos implicitamente admitindo que, a menos que haja informação sobre o óbito do trabalhador no CNIS, NITs que desaparecem definitivamente do CNIS durante o nosso período de análise não correspondem a mortes, mas apenas a não contribuição do trabalhador ao sistema no período para o qual não dispomos de informação sobre ele.

Tabela 2 - Comparação entre CNIS e PNAD - 2006 a 2008 - Em milhões

\begin{tabular}{lccccc|ccccc}
\hline & \multicolumn{5}{c}{ Pessoas } & \multicolumn{5}{c}{ Contribuições } \\
Coorte & $1940-49$ & $1950-59$ & $1960-69$ & $1970-79$ & $1980-89$ & $1940-49$ & $1950-59$ & $1960-69$ & $1970-79$ & $1980-89$ \\
\hline PNAD & & & & & & & & & \\
$\mathbf{2 0 0 6}$ & 12,2 & 19,2 & 25,2 & 28,2 & 33,8 & 1,7 & 5,6 & 9,3 & 11,2 & 9,3 \\
$\mathbf{2 0 0 7}$ & 12,2 & 19,2 & 25,4 & 28,5 & 33,1 & 1,6 & 5,6 & 9,3 & 11,5 & 10,8 \\
$\mathbf{2 0 0 8}$ & 12,1 & 19,5 & 25,6 & 28,2 & 32,6 & 1,4 & 5,6 & 9,6 & 11,8 & 12,4 \\
CNIS & & & & & & & & & & \\
$\mathbf{2 0 0 6}$ & 8,1 & 15,0 & 20,4 & 24,6 & 22,9 & 1,7 & 5,6 & 9,1 & 11,3 & 8,1 \\
$\mathbf{2 0 0 7}$ & 7,8 & 14,9 & 20,4 & 24,6 & 22,7 & 1,6 & 5,7 & 9,4 & 11,8 & 9,7 \\
$\mathbf{2 0 0 8}$ & 7,5 & 14,9 & 20,4 & 24,5 & 22,6 & 1,5 & 5,8 & 9,8 & 12,4 & 11,3 \\
CNIS/PNAD & & & & & & & & & & \\
2006 & 0,66 & 0,78 & 0,81 & 0,87 & 0,68 & 1,05 & 1,00 & 0,98 & 1,01 & 0,87 \\
$\mathbf{2} 2007$ & 0,64 & 0,78 & 0,80 & 0,86 & 0,69 & 1,02 & 1,02 & 1,01 & 1,02 & 0,90 \\
$\mathbf{2 0 0 8}$ & 0,62 & 0,77 & 0,80 & 0,87 & 0,70 & 1,03 & 1,04 & 1,02 & 1,05 & 0,91 \\
\hline
\end{tabular}

Fonte: Tabela construída com base na amostra do CNIS e da PNAD/IBGE.

Notas: O número de contribuições pelo CNIS é calculado como a soma anual de todas as contribuições dividida por 12. As contribuições previdenciárias da PNAD referem-se a qualquer trabalho (principal e secundários) do trabalhador. Somente indivíduos entre 15 e 70 anos foram considerados.

Consideramos que esse critério faz com que seja pequena a possibilidade de falha de identificação e por isto vamos ignorar a sobre-enumeração dos indivíduos. Os resultados apresentados são consistentes, uma vez que a contagem dos contribuintes é razoavelmente precisa e a contagem dos indivíduos mostra que: 1) as coortes mais jovens que tiveram menos chance de contribuir para a previdência apresentam maior evasão; ${ }^{17}$ 2) as coortes mais velhas - que têm entre

17 Proporção de pessoas na coorte que nunca contribuiu. 
55 e 65 anos - também mostram maior evasão por conta de que tem um maior contingente de aposentados; e, 3) a taxa de evasão mínima de aproximadamente $10 \%$ parece razoável.

A Tabela 3 mostra algumas estatísticas descritivas por coorte de nascimento do maior grupo de trabalhadores (grupo P0, a ser descrito na seção a seguir) que utilizaremos para avaliar o impacto do PSPS. A tabela revela que nossa amostra é predominante composta por homens e trabalhadores mais velhos. O Salário de Contribuição, que corresponde ao valor sobre o qual a contribuição previdenciária é realizada, é mais elevado para as coortes mais antigas e mais alto para os homens. O mesmo tipo de padrão é observado para o acúmulo de contribuições realizadas ao longo da vida contributiva dos trabalhadores.

Tabela 3 - Estatísticas descritivas por coorte de nascimento

\begin{tabular}{|c|c|c|c|c|c|c|c|c|c|}
\hline \multirow[t]{2}{*}{ Coorte } & \multicolumn{2}{|c|}{$\begin{array}{l}\text { Proporção de } \\
\text { trabalhadores }\end{array}$} & \multirow[t]{2}{*}{$\begin{array}{l}\text { Proporção } \\
\text { de homens }\end{array}$} & \multicolumn{3}{|c|}{ Salário de Contribuição } & \multicolumn{3}{|c|}{$\begin{array}{l}\text { Número acumulado } \\
\text { de contribuições }\end{array}$} \\
\hline & $\mathrm{H}$ & M & & $\mathrm{H}$ & $\mathrm{M}$ & total & $\mathrm{H}$ & M & total \\
\hline $1940-1949$ & 0.29 & 0.31 & 0.53 & 2.6 & 1.8 & 2.2 & 177 & 128 & 157 \\
\hline $1950-1959$ & 0.35 & 0.34 & 0.55 & 2.1 & 1.6 & 1.9 & 146 & 114 & 133 \\
\hline $1960-1969$ & 0.31 & 0.30 & 0.55 & 1.8 & 1.7 & 1.8 & 76 & 65 & 71 \\
\hline $1970-1979$ & 0.05 & 0.06 & 0.50 & 1.6 & 1.5 & 1.5 & 24 & 22 & 23 \\
\hline 1980-1989 & 0.00 & 0.00 & & & & & 8 & 7 & 7 \\
\hline total & 1.00 & 1.00 & 0.54 & 2.2 & 1.7 & 2.0 & 99 & 78 & 91 \\
\hline
\end{tabular}

Fonte: Tabela construída com base na amostra do CNIS.

Nota: As estatísticas se referem ao grupo P0, que será utilizado na avaliação do impacto do PSPS (ver seção 4 para uma descrição desse grupo). O Salário de Contribuição (SC) médio corresponde ao valor médio sobre o qual o trabalhador recolheu a contribuição previdenciária durante o período de análise (abril de 2005 a março de 2009). O SC está medido em unidades do valor do salário mínimo corrente à contribuição. O número acumulado de contribuições está medido em meses. 


\section{Estimação do Impacto do PSPS}

\subsection{Metodologia}

Para isolar o efeito do PSPS de outros eventos que podem afetar a decisão de contribuir dos trabalhadores, adotaremos a abordagem de diferenças-em-diferenças. ${ }^{18}$ Especificamente, será comparado o comportamento contributivo de um grupo de trabalhadores com maior chance de serem afetados pelo PSPS (grupo de tratamento) com o de um grupo de trabalhadores potencialmente não afetados pelo programa (grupo de controle). Essa comparação entre os dois grupos será realizada ao longo de oito semestres, sendo quatro antes e quatro depois do lançamento do programa. O efeito estará adequadamente isolado se as probabilidades de contribuição voluntária dos grupos de tratamento e de controle antes do PSPS evoluírem de modo semelhante. Neste caso, a diferença de probabilidades entre os grupos será (aproximadamente) constante antes do programa, e qualquer alteração nessa diferença que se verifique após o evento pode ser atribuída ao PSPS.

A escolha do período antes do programa (i.e., dos quatro semestres pré-programa) foi baseada na análise de se a diferença de probabilidades de contribuição entre os grupos era estatisticamente zero. Essa análise mostrou que essa diferença se tornava estatisticamente nula para quase todos os semestres anteriores ao PSPS quando não utilizávamos o primeiro trimestre de 2007. Assim, optamos retirar os primeiros três meses do ano de 2007 do cômputo do impacto do programa, ou seja, nosso período pré-programa ficou demarcado pelos quatro semestres compreendidos entre janeiro de 2005 e dezembro de 2006. ${ }^{19}$ As razões que podem explicar por que o primeiro trimestre de 2007 apresenta tendências distintas entre os grupos são variadas, incluindo o que se costuma denominar de efeito antecipatório por parte dos trabalhadores, ou a possibilidade de que pelo menos uma parte das contribuições referentes a esses primeiros meses de 2007 tenham sido realizadas com a alíquota menor permitida pelo PSPS. ${ }^{20}$

${ }^{18}$ Para resenhas metodológicas sobre esta abordagem, ver $e$.g. Blundell e Dias $(2000,2009)$ e Meyer (1995).

${ }^{19}$ Especificamente, consideramos os seguintes semestres pré-programa: janeiro/2005 a junho/2005, julho/2005 a dezembro/2005; janeiro/2006 a junho/2006; e, julho/2006 a dezembro/2006; Já os quatro semestres pós-programa são: abril/2007 a setembro/2007; outubro/2007 a março/2008; abril/2008 a setembro/2008; e, outubro/2008 a março/2009.

$20 \mathrm{O}$ CNIS informa a data de competência da contribuição, portanto uma contribuição que é 
A abordagem de diferenças-em-diferenças requer a estimativa da probabilidade de contribuir de forma voluntária, e a definição de um critério para distinguir os grupos de tratamento e controle. Para estimar a probabilidade de contribuir, será utilizado o histórico previdenciário completo dos trabalhadores ativos, que inclui os períodos em que o trabalhador não está contribuindo.

A demarcação dos grupos de tratamento e controle foi baseada em faixas salariais, de modo semelhante ao que tem sido amplamente utilizado na literatura que investiga os efeitos do salário mínimo sobre o nível de emprego e os salários (e.g., Card e Kruger (1994, 1997), Fajnzylber (2001), Corseuil e Carneiro (2001), Neumark et al. (2006)).

Vamos definir o salário típico de um contribuinte autônomo como a média do seu salário de contribuição normalizado com o salário mínimo corrente para o período anterior ao lançamento do PSPS (i.e., de janeiro/2005 a dezembro/2006). O salário típico é considerado como uma medida de produtividade do trabalhador em determinado instante de sua vida. Essa construção ignora a evolução da curva salarial e eventuais flutuações de renda ao longo do ciclo de vida, mas pode ser considerada uma aproximação razoável quando a janela de tempo é curta. ${ }^{21}$

Como os trabalhadores que têm acesso ao PSPS devem ter o salário de contribuição igual a $1 \mathrm{SM}$, definimos como o grupo de tratamento os trabalhadores que têm salário de contribuição igual a $1 \mathrm{em}$ todo o período anterior ao PSPS, e como grupo de controle os que tem salário típico no intervalo entre 1,05 e 2 SMs. Os contribuintes que podem optar pelo PSPS são os contribuintes voluntários não empregados, de modo que nosso universo de análise ficou restrito a trabalhadores nessa situação. A contribuição relativa a empregadas domésticas é realizada pelo empregador de forma compulsória. A flexibilidade deste tipo de vínculo permite a mudança do tipo de relação de trabalho. Nas duas situações, o PSPS pode ter induzido uma modificação na relação de trabalho e por isso vão ser consideradas quatro alternativas que combinam duas definições de contribuinte voluntário - excluindo ou não as empregadas domésticas -, e

efetivamente realizada depois do PSPS pode ser lançada com data anterior.

${ }^{21}$ A renda ou o salário de contribuição do trabalhador ativo não contribuinte não é conhecido, por isso admitiu-se que esta característica é estável e pode ser medida com o valor médio dos salários de contribuição observados. 
duas definições para o tipo de contribuinte que é afetado pelo PSPS - os que têm pelo menos uma contribuição voluntária ou os que têm pelo menos uma contribuição voluntária e não têm contribuição compulsória.

O salário de contribuição é uma decisão do contribuinte individual, e o PSPS pode ter afetado a escolha desse valor, assim como a flutuação do salário de contribuição ao longo dos meses do período em estudo. A Tabela 4 apresenta a distribuição do salário de contribuição medido em salários mínimos separadamente para os grupos de tratamento e controle e para os meses dos períodos anterior e posterior ao PSPS. A tabulação foi repetida considerando dois critérios para a empregada doméstica, devido à possível ambiguidade do tipo de relação de trabalho desse grupo já discutida.

Como esperado, a Tabela 4 mostra que o grupo de tratamento é basicamente constituído de trabalhadores que contribuíram sobre l salário mínimo e que uma proporção bastante menor dos salários de contribuição do grupo de controle refere-se a 1 salário mínimo. A Tabela 4 também mostra que há algumas mudanças na distribuição de salários de contribuição entre os períodos pré e pós-PSPS. De fato, observa-se um pequeno espalhamento dos salários de contribuição do grupo de tratamento de 1 salário mínimo para outras faixas da distribuição, ao passo que para o grupo de controle ocorre um aumento da parcela dos salários de contribuição tanto para cima quanto para baixo da distribuição.

Este resultado decorre diretamente da forma com que o grupo de tratamento foi definido - conjunto dos contribuintes que têm o Salário de Contribuição (SC) exatamente igual a um salário mínimo no período pré-PSPS - e do fato de que é ilegal realizar contribuições com valor inferior ao salário mínimo corrente. No período pós PSPS, qualquer elemento do grupo de tratamento só pode declarar mais do que o salário mínimo, o que, portanto, leva ao espalhamento assimétrico observado. Já os elementos do grupo de controle podem ter o seu SC alterado de forma irrestrita, pois podem ter declarado mais do que um salário mínimo em algum período, o que justifica o espalhamento nas duas direções. O que a Tabela 4 mostra para as duas definições - considerando ou não a empregada doméstica como autônoma - é que não se observa uma diferença expressiva nas distribuições dos grupos de tratamento e controle, antes e depois do PSPS 
e, portanto, não temos evidências de que o PSPS tenha alterado de forma expressiva os SC declarados.

Tabela 4 - Distribuição dos salários de contribuição medidos em termos do salário mínimo corrente

\begin{tabular}{|c|c|c|c|c|c|c|c|c|}
\hline \multirow{3}{*}{$\begin{array}{l}\text { Salário de } \\
\text { Contribuição - SC } \\
\text { (em SMs) }\end{array}$} & \multicolumn{4}{|c|}{$\begin{array}{l}\text { Empregada Doméstica } \\
\text { não é autônoma }\end{array}$} & \multicolumn{4}{|c|}{$\begin{array}{c}\text { Empregada Doméstica } \\
\text { é autônoma }\end{array}$} \\
\hline & \multicolumn{2}{|c|}{ Antes do PSPS } & \multicolumn{2}{|c|}{ Depois PSPS } & \multicolumn{2}{|c|}{ Antes do PSPS } & \multicolumn{2}{|c|}{ Depois PSPS } \\
\hline & $T$ & C & T & c & $T$ & c & T & c \\
\hline $\mathrm{SC}=1$ & 1,00 & 0,29 & 0,93 & 0,32 & 1,00 & 0,25 & 0,93 & 0,32 \\
\hline $1<\mathrm{SC} \leq 2$ & 0,00 & 0,65 & 0,05 & 0,54 & 0,00 & 0,69 & 0,05 & 0,56 \\
\hline $2<\mathrm{SC} \leq 3$ & 0,00 & 0,05 & 0,01 & 0,08 & 0,00 & 0,05 & 0,01 & 0,07 \\
\hline$S C>3$ & 0,00 & 0,01 & 0,01 & 0,06 & 0,00 & 0,01 & 0,01 & 0,05 \\
\hline Total & 1,00 & 1,00 & 1,00 & 1,00 & 1,00 & 1,00 & 1,00 & 1,00 \\
\hline
\end{tabular}

Fonte: Tabela construída com base na amostra do CNIS.

Nota: O salário de contribuição mensal informado no CNIS foi dividido pelo valor do salário mínimo do mês correspondente. Antes do PSPS se refere ao período entre janeiro de 2005 e dezembro de 2006; depois do PSPS corresponde ao período entre janeiro de 2007 e março de 2009, excluindo o período de janeiro a março de 2007. Os grupos de tratamento e controle estão referidos por $\mathrm{T}$ e $\mathrm{C}$, respectivamente.

Os grupos de tratamento e controle têm uma distribuição de SC diferente, mas apresentam a mesma tendência para a probabilidade de contribuir para a previdência antes do PSPS, e este é o nosso principal resultado. Formalmente, vamos comparar os grupos de tratamento - ou seja, dos trabalhadores que tiveram pelo menos uma contribuição após o ano de 1999, e que declaram exatamente 1 salário mínimo no período de janeiro de 2005 a dezembro de 2006, e que por definição têm direito de utilizar o PSPS - com o grupo de controle que declarou o SC no intervalo de [1.05,2] salários mínimos e estimar a diferença da probabilidade de contribuir entre estes grupos nos semestres antes e depois do PSPS.

Nossa pergunta refere-se a um grupo de contribuintes específico que é definido segundo critérios derivados do CNIS, o que mitiga o efeito de questões sobre as limitações do CNIS discutidas anteriormente. No entanto, isso coloca algumas limitações, como, por exemplo, 
a de não pretendermos estimar o efeito do PSPS sobre a entrada de novos contribuintes, ou seja, indivíduos que não contribuíram antes do PSPS e que passaram a contribuir. Nesse sentido, nossos resultados podem ser vistos como uma subestimativa do efeito do PSPS.

\subsection{Modelo}

O número de contribuições já realizadas por um trabalhador - o que aqui se denominará ativo previdenciário $A P$ - e a sua idade (Id) são determinantes da probabilidade de contribuição e do valor da próxima contribuição, uma vez que quanto maior o valor destas variáveis, menos o contribuinte precisa investir em tempo e dinheiro para adquirir o direito à aposentadoria. ${ }^{22} \mathrm{O}$ modelo incorpora essas duas variáveis com termos lineares e quadráticos, e é completado com variáveis indicadoras que identificam se o contribuinte $(n)$ faz parte do grupo de tratamento, e se o mês $t$ faz parte do semestre $k$. Os coeficientes foram estimados utilizando-se o seguinte modelo Probit:

$\operatorname{Pr}\left(\mathrm{CI}_{\mathrm{nt}}=1 \mid \mathrm{z} ; \theta\right)=\Phi\left(\alpha+\mathrm{X}_{\mathrm{nt}} \beta+\sum_{\mathrm{k}} \lambda_{\mathrm{k}} \mathrm{E}_{\mathrm{tk}}+\gamma \mathrm{T}_{\mathrm{n}}+\sum_{\mathrm{k}} \eta_{\mathrm{k}} \mathrm{E}_{\mathrm{tk}} \mathrm{T}_{\mathrm{n}}\right)=\Phi\left(\mathrm{z}_{\mathrm{n}} \theta\right), \mathrm{n} \in \mathrm{P}$

No modelo, $\Phi($.$) representa a distribuição acumulada da normal pa-$ drão, $z_{n}=\left(1, \mathrm{X}, \mathrm{E}_{1}, \ldots \mathrm{E}_{6}, \mathrm{~T}\right)_{\mathrm{n}}$ é o vetor de variáveis observadas e $\theta$ $=\left(\alpha, \beta, \lambda_{1}, \ldots, \lambda_{6}, \gamma, \eta_{1}, \ldots, \eta_{6}\right)^{\prime}$ o vetor de parâmetros a serem estimados. CI assume valor unitário se houve contribuição voluntária e valor zero caso contrário, o vetor $X$ é composto das variáveis $X=$ (AP, Id, $\left.\mathrm{AP}^{2}, \mathrm{Id}^{2}, \mathrm{Id}^{*} \mathrm{AP}\right), T$ é uma variável binária com valor unitário se o trabalhador pertence ao grupo de tratamento e valor zero se pertence ao grupo de controle, $E_{t k}$ é uma variável dummy que é igual a um se a observação se refere ao mês $t$ do semestre $k=1, \ldots$, 8. Nossos parâmetros de interesse são representados por $\eta_{k}$.

$P$ denota o universo de análise para o qual o modelo é estimado. Considerou-se $P O$ o conjunto dos trabalhadores que: $i$ ) tiveram pelo menos uma contribuição voluntária não nula entre janeiro de 2005 e março de 2007; e ii) tiveram salário de contribuição médio real menor que quatro vezes o valor do SM real deste período.

${ }^{22} \mathrm{O}$ ativo previdenciário associado a um NIT foi calculado considerando todo o histórico disponível de contribuições associado àquele NIT. As limitações relacionadas às possíveis duplicidades de NITs fazem com que esta medida subenumere as contribuições efetivas para todos os trabalhadores que tiveram mais de um NIT. 
O comportamento do contribuinte que migra entre os dois tipos básicos de contribuição - voluntária ou compulsória - determina o seu perfil contributivo, e pode ser relevante na decisão de contribuir. Por isto foi definido também um subconjunto, $P 1$, que exclui de $P 0$ todos os contribuintes que não são estritamente voluntários.

Em oposição ao caso de um empregado formal, em que a totalidade das contribuições é compulsória, quando todas as contribuições são voluntárias, temos o caso dos profissionais autônomos que vão formar o grupo Pl. Esses dois grupos podem ter um comportamento distinto e o foco do PSPS são os contribuintes voluntários, por isso decidimos realizar um exercício considerando apenas o grupo Pl. O grupo P0 é mais amplo que o Pl, pois inclui qualquer trabalhador que contribuiu pelo menos uma vez de forma voluntária. $\mathrm{Na}$ medida em que o PSPS pode afetar a frequência de contribuições voluntárias em geral, o grupo P0 torna-se um grupo importante para se avaliar o efeito do programa.

O empregado doméstico em princípio não pode optar pelo PSPS, mas como este tipo de trabalhador tem uma relação mais próxima com o seu empregador, é possível que, em face do PSPS, resolva passar a contribuinte voluntário. Por isto foram adotadas duas definições para a caracterização do contribuinte voluntário:

- D1: todas as contribuições do tipo contribuinte individual, o que implica considerar a contribuição do empregado doméstico como voluntário; e,

- D2: todas as contribuições do tipo contribuinte individual que não sejam de empregados domésticos

Sendo o modelo Probit não linear, o efeito sobre a probabilidade de participação do grupo de tratamento não é medido diretamente pelos coeficientes $\eta$ relativos à interação da variável indicadora de tratamento $(T)$ e da indicadora do período $(E)$. Para se estimar o efeito num caso análogo, Puhani (2008) propôs que se utilizasse a Expressão (2) abaixo, na qual o efeito do PSPS condicional a $\mathrm{X}=\mathrm{x}$ é medido por $\pi_{\mathrm{k}}(\theta \mid \mathrm{x})$ para os semestres $k$ posteriores à introdução do PSPS.

$$
\begin{gathered}
\pi_{\mathrm{k}}(\theta \mid \mathrm{x})=\mathrm{E}\left\{\mathrm{P}\left(\mathrm{CI}_{\mathrm{nt}}=1 \mid \mathrm{x}, \mathrm{T}=1, \mathrm{E}_{\mathrm{k}}=1, \theta\right)\right\}-\mathrm{E}\left\{\mathrm{P}\left(\mathrm{CI}_{\mathrm{nt}}=1 \mid \mathrm{x}, \mathrm{T}=0, \mathrm{E}_{\mathrm{k}}=1, \theta\right)\right\} \\
=\Phi\left(\mathrm{x}^{\prime} \beta+\lambda_{\mathrm{k}}+\gamma+\eta_{\mathrm{k}}\right)-\Phi\left(\mathrm{x}^{\prime} \beta+\lambda_{\mathrm{k}}+\gamma\right)
\end{gathered}
$$


A Expressão (2) é não linear e pode ser calculada para valores particulares dos vetores de parâmetros e das variáveis de controle. No entanto: (1) o vetor $\theta$ é estimado e conhecemos apenas a sua distribuição de probabilidade $\theta \sim N(m, v)$; e (2) x é observado e dispomos apenas de uma amostra aleatória $\left\{\mathrm{x}_{1}, \ldots, \mathrm{x}_{\mathrm{n}}\right\}$.

Estamos interessados em medir o efeito do PSPS de forma não condicional, isto é, obtendo a média dos efeitos para os diferentes valores de X. A distribuição de probabilidade empírica desses efeitos pode ser calculada com o estimador de Monte Carlo (Ripley (1987) ou Robert e Casella (2004)). Para tanto, seja uma sequência de realizações da distribuição $\theta^{\mathrm{i}} \sim N(m, v)$ do vetor de parâmetros $\Theta=\left\{\theta^{1}, \ldots\right.$. $\left.\theta^{\mathrm{n}}\right\}$, então a distribuição empírica desses efeitos é dada por:

$$
\Pi_{\mathrm{k}}=\left\{\pi_{\mathrm{k}}\left(\theta^{1} \mid \mathrm{x}_{1}\right), \ldots \ldots, \pi_{\mathrm{k}}\left(\theta^{\mathrm{n}} \mid \mathrm{x}_{\mathrm{n}}\right)\right\}
$$

Com esta distribuição podemos calcular qualquer estatística, em particular o valor esperado: $\mathrm{E}\left(\Pi_{\mathrm{k}}\right)$, a variância $\mathrm{V}\left(\Pi_{\mathrm{k}}\right)$ e o intervalo de confiança desse efeito. $\mathrm{O}$ modelo foi estimado separadamente por sexo e para as populações $P 0$ e $P 1$. Em cada caso, as estimativas foram computadas para as amostras definidas por D1 e D2.

\section{Resultados}

A Tabela 5, baseada na amostra D1, exibe as estimativas das diferenças de probabilidade de contribuição entre os grupos de tratamento e controle para os semestres anteriores e posteriores ao programa. ${ }^{23} \mathrm{As}$ estimativas são não condicionais, pois se referem ao valor esperado das diferenças obtidas para a amostra de contribuintes. Somente as diferenças de probabilidade entre os grupos para os quatro últimos semestres representam o impacto propriamente dito do programa.

${ }^{23}$ Como na estimação do modelo Probit a dummy referente ao primeiro semestre foi a omitida, os resultados são apresentados para os semestres posteriores a este. 
Tabela 5 - Efeito do tratamento por tipo de população considerando empregados domésticos como contribuintes voluntários (D1) - Não condicional

\begin{tabular}{lccccccccc}
\hline & \multicolumn{2}{c}{ Mulheres, P0 } & \multicolumn{2}{c}{ Homens, P0 } & \multicolumn{2}{c}{ Mulheres, P1 } & \multicolumn{2}{c}{ Homens, P1 } \\
Semestre & Dif. & EP & Dif. & EP & Dif. & EP & Dif. & EP \\
\hline $\begin{array}{l}\text { Jul/2005 } \\
\text { Dez/2005 }\end{array}$ & -0.0118 & 0.0093 & -0.0012 & 0.0091 & -0.0120 & 0.0109 & $-0.0196^{*}$ & 0.0117 \\
Jan/2006 & & & & & & & & \\
Jun/2006 & -0.0113 & 0.0093 & 0.0111 & 0.0092 & -0.0120 & 0.0108 & -0.0037 & 0.0105 \\
$\begin{array}{l}\text { Jul/2006 } \\
\text { Dez/2006 }\end{array}$ & 0.0112 & 0.0093 & $0.0160^{*}$ & 0.0095 & 0.0097 & 0.0107 & -0.0089 & 0.0107 \\
$\begin{array}{l}\text { Abr/2007 } \\
\text { Set/2007 }\end{array}$ & $0.0263^{* * *}$ & 0.0094 & $0.0508^{* * *}$ & 0.0105 & $0.0230^{* *}$ & 0.0116 & $0.0272^{* *}$ & 0.0126 \\
$\begin{array}{l}\text { Out/2007 } \\
\text { Mar/2008 }\end{array}$ & $0.0392^{* * *}$ & 0.0098 & $0.0603^{* * *}$ & 0.0113 & $0.0235^{* *}$ & 0.0114 & $0.0364^{* * *}$ & 0.0137 \\
$\begin{array}{l}\text { Abr/2008 } \\
\text { Set/2008 }\end{array}$ & $0.0409^{* * *}$ & 0.0100 & $0.0588^{* * *}$ & 0.0114 & $0.0188^{*}$ & 0.0110 & $0.0376^{* * *}$ & 0.0138 \\
$\begin{array}{l}\text { Out/2008 } \\
\text { Mar/2009 }\end{array}$ & $0.0481^{* * *}$ & 0.0110 & $0.0795^{* * *}$ & 0.0140 & $0.0235^{* *}$ & 0.0112 & $0.0579^{* * *}$ & 0.0171 \\
& & & & & & & & \\
Observ. & 186815 & & 194944 & & 145328 & & 142463 & \\
NITs & 4044 & & 4208 & & 3143 & & 3066 & \\
\hline
\end{tabular}

Fonte: Estimação realizada com base na amostra do CNIS.

Notas: Dif. refere-se à diferença da probabilidade esperada entre os grupos de tratamento e controle por semestre. EP corresponde ao erro padrão. Utilizou-se o método de Puhani (2008) descrito no texto. Níveis de significância: ${ }^{*}=10 \%,{ }^{* *}=5 \%$ e ${ }^{* * *}=1 \%$.

Como discutido anteriormente, o método de diferenças-em-diferenças requer que o grupo de controle apresente a mesma tendência que o grupo de tratamento para a variável de interesse antes do início do programa. Como mostra a Tabela 5, esse requerimento é quase sempre atendido, já que as estimativas das diferenças de probabilidade de contribuição entre os grupos são estatisticamente zero para praticamente todos os semestres anteriores ao programa. As estimativas dos coeficientes do modelo Probit, que se encontram na Tabela 6, permitem ratificar essa afirmação. ${ }^{24}$

\footnotetext{
${ }^{24}$ Nota-se que, apesar de a estimação do modelo Probit não permitir fazer inferências diretas sobre as diferenças de contribuição entre os grupos de tratados e controles (incluindo o impacto médio do programa), as estimativas dos coeficientes e erros-padrão dos termos de interação fornecem alguma indicação sobre a significância estatística dessas diferenças.
} 
Tabela 6 - Estimativas do modelo Probit para diferentes grupos

\begin{tabular}{|c|c|c|c|c|c|c|c|c|}
\hline & \multicolumn{4}{|c|}{ D1 } & \multicolumn{4}{|c|}{ D2 } \\
\hline & \multicolumn{2}{|c|}{ PO } & \multicolumn{2}{|c|}{ P1 } & \multicolumn{2}{|c|}{ PO } & \multicolumn{2}{|c|}{ P1 } \\
\hline & Mulher & Homem & Mulher & Homem & Mulher & Homem & Mulher & Homem \\
\hline \multirow{2}{*}{ AP } & 0,0136 & 0,0101 & 0,0262 & 0,0210 & 0,0158 & 0,0104 & 0,0295 & 0,0215 \\
\hline & $(0,0002)$ & $(0,0002)$ & $(0,0003)$ & $(0,0003)$ & $(0,0002)$ & $(0,0002)$ & $(0,0003)$ & $(0,0003)$ \\
\hline \multirow{2}{*}{ Idade } & $-0,0006$ & $-0,0036$ & $-0,0050$ & $-0,0092$ & $-0,0012$ & $-0,0038$ & $-0,0055$ & $-0,0093$ \\
\hline & $(0,0001)$ & $(0,0001)$ & $(0,0002)$ & $(0,0002)$ & $(0,0001)$ & $(0,0001)$ & $(0,0001)$ & $(0,0002)$ \\
\hline \multirow{2}{*}{$\mathrm{AP}^{2}$} & $-31,6932$ & $-19,0368$ & $-32,7035$ & $-10,3044$ & $-34,8524$ & $-19,6614$ & $-35,5027$ & $-11,1831$ \\
\hline & $(0,3715)$ & $(0,3363)$ & $(0,4860)$ & $(0,5644)$ & $(0,3599)$ & $(0,3340)$ & $(0,4678)$ & $(0,5560)$ \\
\hline \multirow{2}{*}{ Idade $^{2}$} & 0,8956 & 2,8292 & 4,5329 & 7,5893 & 1,4123 & 2,9694 & 5,1028 & 7,7086 \\
\hline & $(0,1273)$ & $(0,1344)$ & $(0,1573)$ & $(0,1763)$ & $(0,1135)$ & $(0,1339)$ & $(0,1409)$ & $(0,1746)$ \\
\hline \multirow{2}{*}{ AP*Idade } & $-2,4585$ & $-0,5424$ & $-18,9880$ & $-17,5710$ & $-4,5222$ & $-0,7242$ & $-22,8540$ & $-17,9093$ \\
\hline & $(0,3697)$ & $(0,3391)$ & $(0,5003)$ & $(0,4797)$ & $(0,3486)$ & $(0,3350)$ & $(0,4688)$ & $(0,4734)$ \\
\hline \multirow{2}{*}{ Sem2 } & 0,0661 & 0,0562 & 0,0691 & 0,1164 & 0,0459 & 0,0538 & 0,0500 & 0,1193 \\
\hline & $(0,0206)$ & $(0,0203)$ & $(0,0258)$ & $(0,0258)$ & $(0,0169)$ & $(0,0198)$ & $(0,0202)$ & $(0,0252)$ \\
\hline \multirow{2}{*}{ Sem3 } & 0,1140 & 0,0675 & 0,1186 & 0,1231 & 0,1008 & 0,0545 & 0,1185 & 0,1151 \\
\hline & $(0,0206)$ & $(0,0203)$ & $(0,0258)$ & $(0,0258)$ & $(0,0169)$ & $(0,0199)$ & $(0,0202)$ & $(0,0252)$ \\
\hline \multirow{2}{*}{ Sem4 } & 0,1217 & 0,0928 & 0,1220 & 0,1854 & 0,1016 & 0,0748 & 0,1182 & 0,1715 \\
\hline & $(0,0206)$ & $(0,0203)$ & $(0,0257)$ & $(0,0260)$ & $(0,0169)$ & $(0,0199)$ & $(0,0201)$ & $(0,0253)$ \\
\hline \multirow{2}{*}{ Sem5 } & $-0,0402$ & $-0,0657$ & $-0,0273$ & 0,0188 & $-0,0654$ & $-0,0853$ & $-0,0315$ & 0,0021 \\
\hline & $(0,0205)$ & $(0,0203)$ & $(0,0254)$ & $(0,0256)$ & $(0,0168)$ & $(0,0198)$ & $(0,0199)$ & $(0,0250)$ \\
\hline \multirow{2}{*}{ Sem6 } & $-0,1769$ & $-0,1632$ & $-0,1281$ & $-0,0734$ & $-0,1810$ & $-0,1761$ & $-0,1203$ & $-0,0833$ \\
\hline & $(0,0205)$ & $(0,0203)$ & $(0,0254)$ & $(0,0255)$ & $(0,0168)$ & $(0,0198)$ & $(0,0199)$ & $(0,0249)$ \\
\hline \multirow{2}{*}{ Sem7 } & $-0,2505$ & $-0,2034$ & $-0,1889$ & $-0,1085$ & $-0,2679$ & $-0,2142$ & $-0,1986$ & $-0,1164$ \\
\hline & $(0,0205)$ & $(0,0203)$ & $(0,0254)$ & $(0,0255)$ & $(0,0168)$ & $(0,0198)$ & $(0,0198)$ & $(0,0249)$ \\
\hline \multirow{2}{*}{ Sem8 } & $-0,3468$ & $-0,3010$ & $-0,2781$ & $-0,2093$ & $-0,3670$ & $-0,3107$ & $-0,2952$ & $-0,2132$ \\
\hline & $(0,0206)$ & $(0,0204)$ & $(0,0253)$ & $(0,0255)$ & $(0,0169)$ & $(0,0199)$ & $(0,0198)$ & $(0,0249)$ \\
\hline \multirow{2}{*}{ Trat. } & $-0,0925$ & $-0,1363$ & $-0,1021$ & $-0,1223$ & $-0,2115$ & $-0,1510$ & $-0,1741$ & $-0,1281$ \\
\hline & $(0,0179)$ & $(0,0176)$ & $(0,0218)$ & $(0,0219)$ & $(0,0157)$ & $(0,0173)$ & $(0,0183)$ & $(0,0215)$ \\
\hline \multirow{2}{*}{ Sem $2^{\star}$ Trat. } & $-0,0325$ & $-0,0033$ & $-0,0374$ & $-0,0606$ & $-0,0105$ & $-0,0023$ & $-0,0167$ & $-0,0656$ \\
\hline & $(0,0254)$ & $(0,0248)$ & $(0,0309)$ & $(0,0311)$ & $(0,0221)$ & $(0,0244)$ & $(0,0258)$ & $(0,0305)$ \\
\hline \multirow{2}{*}{ Sem3 ${ }^{*}$ Trat. } & $-0,0311$ & 0,0304 & $-0,0351$ & $-0,0116$ & $-0,0418$ & 0,0407 & $-0,0621$ & $-0,0081$ \\
\hline & $(0,0254)$ & $(0,0249)$ & $(0,0309)$ & $(0,0311)$ & $(0,0221)$ & $(0,0245)$ & $(0,0258)$ & $(0,0305)$ \\
\hline \multirow{2}{*}{ Sem $4^{\star}$ Trat. } & 0,0310 & 0,0442 & 0,0298 & $-0,0278$ & 0,0165 & 0,0596 & $-0,0095$ & $-0,0189$ \\
\hline & $(0,0254)$ & $(0,0249)$ & $(0,0308)$ & $(0,0312)$ & $(0,0221)$ & $(0,0245)$ & $(0,0258)$ & $(0,0306)$ \\
\hline Sem $5 *$ Trat & 0,0726 & 0,1398 & 0,0692 & 0,0842 & 0,0697 & 0,1573 & 0,0362 & 0,0950 \\
\hline Sefins irat. & $(0,0252)$ & $(0,0248)$ & $(0,0305)$ & $(0,0310)$ & $(0,0219)$ & $(0,0244)$ & $(0,0255)$ & $(0,0304)$ \\
\hline Sem $6^{*} \mathrm{Tr}$ & 0,1088 & 0,1669 & 0,0700 & 0,1119 & 0,0862 & 0,1774 & 0,0275 & 0,1161 \\
\hline Sem6“Trat. & $(0,0252)$ & $(0,0248)$ & $(0,0304)$ & $(0,0308)$ & $(0,0220)$ & $(0,0244)$ & $(0,0255)$ & $(0,0302)$ \\
\hline Sem $7 *$ Trat & 0,1148 & 0,1636 & 0,0559 & 0,1152 & 0,1078 & 0,1707 & 0,0320 & 0,1158 \\
\hline & $(0,0253)$ & $(0,0248)$ & $(0,0304)$ & $(0,0308)$ & $(0,0220)$ & $(0,0244)$ & $(0,0255)$ & $(0,0303)$ \\
\hline Sem 8*Trat & 0,1374 & 0,2237 & 0,0702 & 0,1773 & 0,1330 & 0,2293 & 0,0520 & 0,1729 \\
\hline Sem8“T rat. & $(0,0254)$ & $(0,0249)$ & $(0,0304)$ & $(0,0308)$ & $(0,0221)$ & $(0,0245)$ & $(0,0255)$ & $(0,0303)$ \\
\hline & $-0,3852$ & 0,5244 & 0,9157 & 2,1012 & $-0,0963$ & 0,5757 & 1,0407 & 2,1208 \\
\hline Constante & $(0,0387)$ & $(0,0386)$ & $(0,0480)$ & $(0,0512)$ & $(0,0333)$ & $(0,0384)$ & $(0,0402)$ & $(0,0505)$ \\
\hline
\end{tabular}

Fonte: Estimação realizada com base na amostra do CNIS.

Notas: Erros-padrão entre parênteses. AP refere-se ao ativo previdenciário acumulado pelo trabalhador, SemJ corresponde à variável dummy do semestre $J=2, \ldots, 8$ (semestre entre janeiro/2005 e junho/2005 omitido), Trat. é a variável dummy que assume valor unitário se o trabalhador faz parte do grupo de tratamento. Para as definições de D1, D2, P0 e $\mathrm{P} 1$, ver texto. 
Em relação aos impactos, os resultados se revelam positivos e estatisticamente significativos tanto para homens quanto para mulheres nas populações $\mathrm{P0}$ e Pl. A magnitude do impacto, entretanto, mostra-se distinta entre os dois sexos, sendo mais elevada para homens. Por exemplo, a Tabela 5 mostra que o efeito estimado para os homens (mulheres) na população P0 é de $5,1(2,6)$ pontos de percentagem (p.p.) no primeiro semestre após o início do programa, passa a cerca de 6 (4) p.p. nos dois semestres seguintes e alcança aproximadamente 8 (5) p.p. no último semestre de nossa análise. Embora com magnitude parecida no primeiro semestre pós-PSPS, a diferença de impacto entre os gêneros também é notável na população Pl. Os Gráficos 2.1 e 2.2, que exibem tanto a diferença de probabilidade de contribuição entre tratados e controle quanto os limites inferior e superior do intervalo de confiança de $95 \%$ dessa diferença, confirma os resultados encontrados para cada grupo de gênero em $\mathrm{P} 0$ e em $\mathrm{Pl}$, respectivamente.

$\mathrm{O}$ resultado referente às mulheres do grupo $\mathrm{Pl}$ destoa dos demais porque não apresenta o crescimento da diferença da probabilidade de contribuição observado nos demais casos. Isto possivelmente decorre da definição deste grupo. Os empregados domésticos não são legalmente contribuintes voluntários e, portanto, não são potencialmente afetados pelo PSPS. No entanto, incluímos essa tabulação porque existe uma situação confusa entre empregado doméstico e diarista, e mesmo alguns empregados podem estar de fato se incluindo como autônomos. As demais colunas dessa tabela mostram que esta ambiguidade de inclusão faz com que o PSPS tenha efeito para todos os casos exceto para um. 


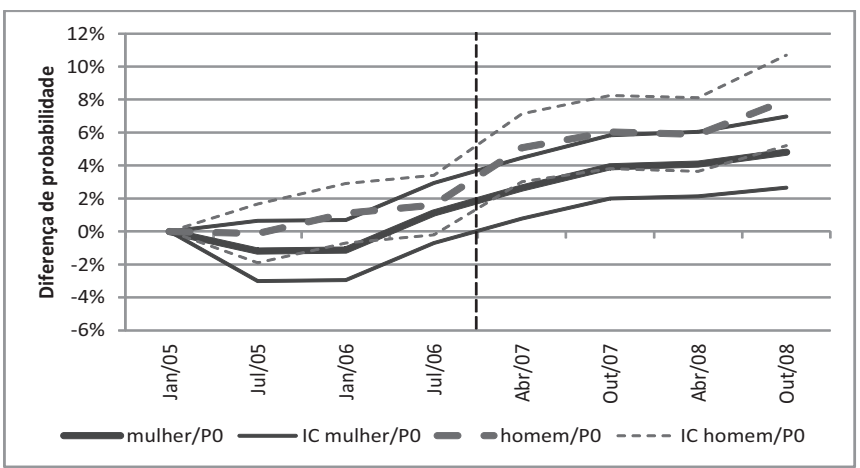

Gráfico 2.1 - Estimativa da diferença e intervalo de confiança da diferença da probabilidade de contribuição entre os grupos de tratamento e controle - Não condicional - Amostra D1|P0

Notas: 1. Grupos: todos os contribuintes $(P 1)$; os que têm apenas contribuição voluntária $(P 0)$; D1: considerando-se empregado doméstico como contribuinte voluntário. Não condicional: média para diferentes valores das variáveis de características dos trabalhadores utilizadas no modelo.

2. As duas curvas mais grossas mostram a diferença de probabilidade de contribuição por semestre e as linhas mais finas o intervalo de confiança (IC) de 95\% para essas diferenças. 3. As estimativas após a linha vertical pontilhada referem-se ao impacto do PSPS.

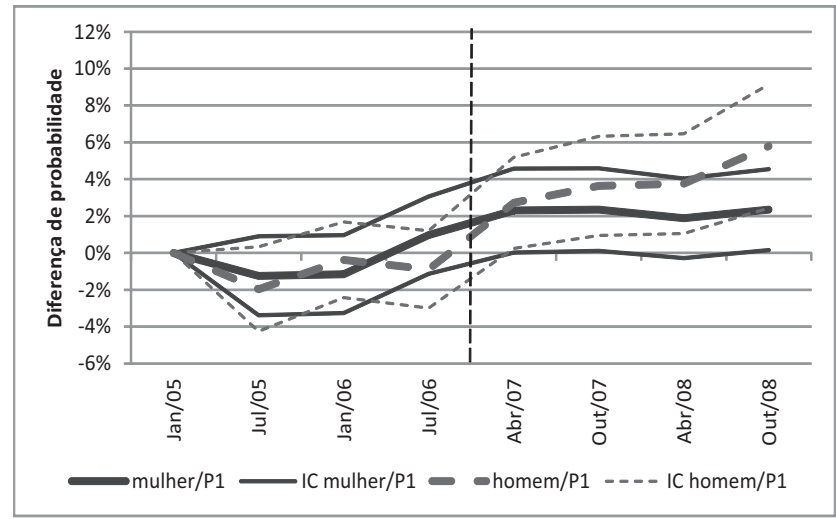

Gráfico 2.2 - Estimativa da diferença e intervalo de confiança da diferença da probabilidade de contribuição entre os grupos de tratamento e controle - Não condicional - Amostra D1|P1

Notas: 1. Grupos: todos os contribuintes $(P 1)$; os que têm apenas contribuição voluntária $(P 0)$; Dl: considerando-se empregado doméstico como contribuinte voluntário. Não condicional: média para diferentes valores das variáveis de características dos trabalhadores utilizadas no modelo.

2. As duas curvas mais grossas mostram a diferença de probabilidade de contribuição por semestre e as linhas mais finas o intervalo de confiança (IC) de 95\% para essas diferenças.

3. As estimativas após a linha vertical pontilhada referem-se ao impacto do PSPS. 
A Tabela 7 e os Gráficos 3.1 e 3.2 repetem a análise para o caso em que os empregados domésticos não são considerados contribuintes voluntários (amostra D2). Exceto para as mulheres do grupo P1, os resultados são qualitativa e quantitativamente semelhantes aos anteriores, pois, além de não evidenciarem tendências marcadamente distintas para os grupos de tratamento e controle pré-programa, ${ }^{25}$ mostram efeitos positivos e estatisticamente significativos para ambos os sexos nas populações $\mathrm{P} 0$ e $\mathrm{Pl}$. No caso das mulheres do grupo $\mathrm{Pl}$, as diferenças não são significativas em todo o período. Este resultado pode ser justificado pelo menos em parte, se lembrarmos de que os empregados domésticos, de fato, não têm direito ao uso do PSPS - e na sua maioria são do sexo feminino. ${ }^{26}$

Tabela 7 - Efeito do tratamento por tipo de população não considerando empregados domésticos como contribuintes voluntários (D2) Não Condicional

\begin{tabular}{|c|c|c|c|c|c|c|c|c|}
\hline \multirow[b]{2}{*}{ Semestre } & \multicolumn{2}{|c|}{ Mulheres, P0 } & \multicolumn{2}{|c|}{ Homens, PO } & \multicolumn{2}{|c|}{ Mulheres, P1 } & \multicolumn{2}{|c|}{ Homens, P1 } \\
\hline & Dif. & EP & Dif. & EP & Dif. & EP & Dif. & EP \\
\hline $\begin{array}{l}\text { Jul/2005 } \\
\text { Dez/2005 }\end{array}$ & $-0,0038$ & 0,0080 & $-0,0008$ & 0,0089 & $-0,0055$ & 0,0089 & $-0,0211^{\star}$ & 0,0117 \\
\hline $\begin{array}{l}\text { Jan/2006 } \\
\text { Jun/2006 }\end{array}$ & $-0,0150^{*}$ & 0,0081 & 0,0148 & 0,0091 & $-0,0205^{\star \star}$ & 0,0101 & $-0,0026$ & 0,0101 \\
\hline $\begin{array}{l}\text { Jul/2006 } \\
\text { Dez/2006 }\end{array}$ & 0,0059 & 0,0080 & $0,0217^{\star *}$ & 0,0092 & $-0,0032$ & 0,0088 & $-0,0060$ & 0,0102 \\
\hline $\begin{array}{l}\text { Abr/2007 } \\
\text { Set/2007 }\end{array}$ & $0,0251^{\star \star \star}$ & 0,0082 & $0,0570^{\star * \star}$ & 0,0108 & 0,0120 & 0,0091 & $0,0306^{* *}$ & 0,0130 \\
\hline $\begin{array}{l}\text { Out/2007 } \\
\text { Mar/2008 }\end{array}$ & $0,0307^{\star \star *}$ & 0,0084 & $0,0638^{* * *}$ & 0,0117 & 0,0092 & 0,0089 & $0,0377^{* \star \star}$ & 0,0139 \\
\hline $\begin{array}{l}\text { Abr/2008 } \\
\text { Set/2008 }\end{array}$ & $0,0381^{\star * *}$ & 0,0089 & $0,0610^{* * *}$ & 0,0118 & 0,0106 & 0,0089 & $0,0377^{\star \star *}$ & 0,0138 \\
\hline $\begin{array}{l}\text { Out/2008 } \\
\text { Mar/2009 }\end{array}$ & $0,0461^{\star \star *}$ & 0,0099 & $0,0809^{* * *}$ & 0,0146 & $0,0172^{*}$ & 0,0092 & $0,0562^{* \star *}$ & 0,0167 \\
\hline Observ. & 231238 & & 199790 & & 187508 & & 146605 & \\
\hline NITs & 5006 & & 4313 & & 4055 & & 3176 & \\
\hline
\end{tabular}

Fonte: Estimação realizada com base na amostra do CNIS.

Notas: Dif. refere-se à diferença da probabilidade esperada entre os grupos de tratamento e controle por semestre. EP corresponde ao erro padrão. Utilizou-se o método de Puhani (2008) descrito no texto. Níveis de significância: $*=10 \%, * *=5 \% \mathrm{e} * * *=1 \%$.

\footnotetext{
${ }^{25}$ Novamente, a Tabela 6 permite corroborar essa afirmação.

${ }^{26}$ Pelos microdados da PNAD para os anos 2000, a parcela de mulheres na categoria de em pregados domésticos era de $93 \%$.
} 


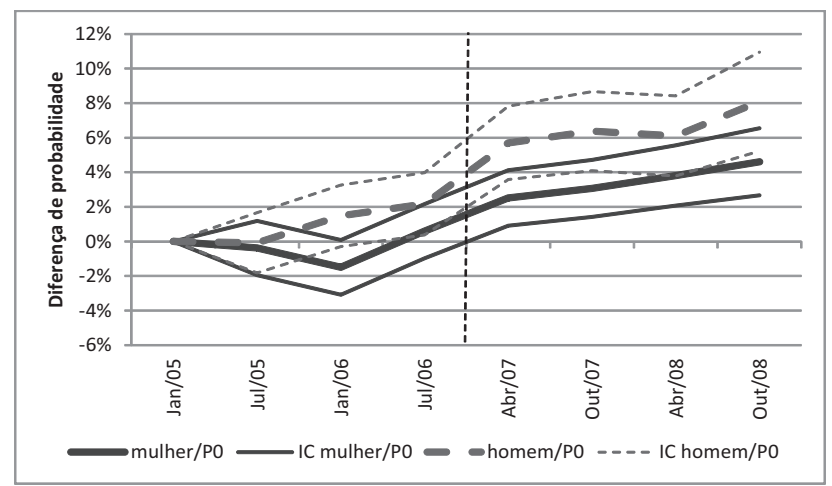

Gráfico 3.1 - Estimativa da diferença e intervalo de confiança da diferença da probabilidade de contribuição entre os grupos de tratamento e controle - Não Condicional - Amostra D2|P0

Notas: 1. Grupos: todos os contribuintes (P1); os que têm apenas contribuição voluntária $(P 0)$; D2: Não considerando empregado doméstico como contribuinte voluntário. Não condicional: média para diferentes valores das variáveis de características dos trabalhadores utilizadas no modelo.

2. As duas curvas mais grossas mostram a diferença de probabilidade de contribuição por semestre e as linhas mais finas o intervalo de confiança (IC) de 95\% para essas diferenças.

3. As estimativas após a linha vertical pontilhada referem-se ao impacto do PSPS.

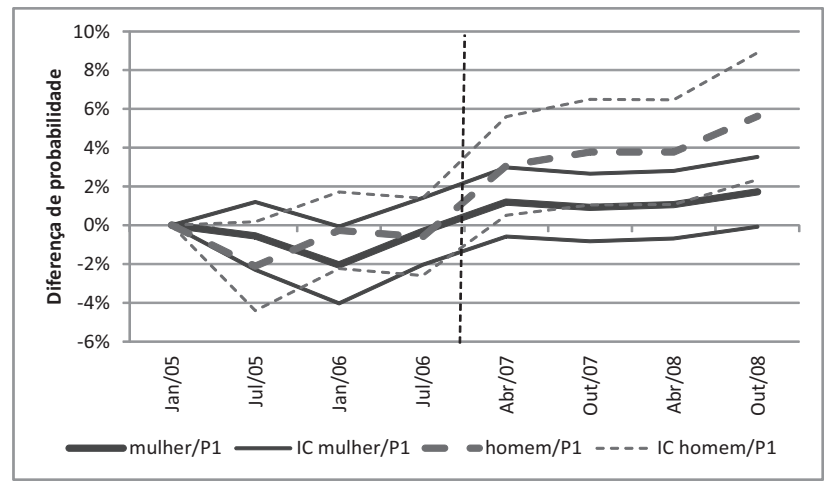

Gráfico 3.2 - Estimativa da diferença e intervalo de confiança da diferença da probabilidade de contribuição entre os grupos de tratamento e controle - Não Condicional - Amostra D2|P1

Notas: 1. Grupos: todos os contribuintes $(P 1)$; os que têm apenas contribuição voluntária $(P 0)$; D2: Não considerando empregado doméstico como contribuinte voluntário. Não condicional: média para diferentes valores das variáveis de características dos trabalhadores utilizadas no modelo.

2. As duas curvas mais grossas mostram a diferença de probabilidade de contribuição por semestre e as linhas mais finas o intervalo de confiança (IC) de 95\% para essas diferenças.

3. As estimativas após a linha vertical pontilhada referem-se ao impacto do PSPS. 
Em suma, pelos resultados obtidos constata-se que o PSPS parece ter tido um efeito positivo sobre a probabilidade de contribuição voluntária à Previdência. Mais especificamente, o programa elevou a proporção de contribuintes voluntários para o grupo de trabalhadores que contribui pelo menos uma vez de forma voluntária ao sistema previdenciário.

\section{Conclusão}

Neste artigo, procuramos avaliar o impacto do PSPS sobre a probabilidade de contribuição voluntária para o sistema de previdência no Brasil. Para tanto, foram utilizados os microdados de uma amostra do CNIS, a mais ampla base de dados administrativa sobre contribuição previdenciária no país. Embora contenha informações limitadas sobre características do trabalhador, essa amostra tem a grande vantagem de possuir o histórico contributivo dos trabalhadores. $\mathrm{O}$ método de identificação do impacto foi o de diferenças-em-diferenças, o qual requer que os grupos de indivíduos afetados (tratamento) e não afetados (controle) pelo programa possuam tendências comuns em relação à variável de interesse (no caso presente, contribuição voluntária à Previdência) antes da introdução da intervenção. Utilizou-se uma versão modificada deste método que simultaneamente permite testar a validade desta condição e estimar o efeito médio do programa. Especificamente, empregamos a abordagem proposta por Puhani (2008), a qual foi implementada utilizando-se o método de Monte Carlo para estimar não apenas o efeito esperado, mas também sua dispersão.

Os resultados atestam que o PSPS aumentou a probabilidade de os trabalhadores que ganham em torno de 1 SM realizarem contribuição voluntária. A abordagem foi repetida para diferentes conjuntos de trabalhadores, de forma a avaliar a robustez dos resultados. Essa análise confirma que cerca de um ano após seu lançamento o PSPS aumentou a probabilidade de contribuição voluntária entre 4 e 6 p.p. para os homens e entre 2 e 4 p.p. para as mulheres. Como a probabilidade média de contribuição voluntária pré-programa é da ordem de $57 \%$ para ambos os sexos, o impacto do PSPS em termos relativos está em torno $9 \%$ para os homens e $5 \%$ para as mulheres. ${ }^{27}$

\footnotetext{
${ }^{27}$ A probabilidade média pré-programa foi calculada para o grupo de contribuintes que realizaram pelo menos uma contribuição voluntária no período entre janeiro de 2005 e dezembro de 2006.
} 
Apesar de o PSPS parecer ter um impacto positivo sobre a contribuição à Previdência, não se pode afirmar o mesmo em relação ao seu efeito sobre a arrecadação líquida do sistema. Em primeiro lugar, porque nossos resultados se referem ao aumento de contribuições daqueles que já contribuíam para o sistema, ou seja, não estamos medindo o impacto do programa sobre a entrada de novos contribuintes. Em segundo lugar, porque a diminuição da alíquota de contribuição não necessariamente eleva a arrecadação bruta da Previdência. Por exemplo, se os que contribuíam acima do salário mínimo decidiram contribuir exatamente sobre o valor deste piso para aproveitar a redução da alíquota, é possível que o total arrecadado com esse grupo diminua. Uma análise do efeito sobre novos entrantes e sobre a decisão de reduzir o salário de contribuição para o valor do mínimo é crucial para se calcular a relação custo-efetividade do programa. Essa análise, no entanto, está fora do escopo deste trabalho.

Os resultados deste trabalho indicam que reduções na alíquota de contribuição voluntária para a Previdência podem ter efeitos positivos sobre participação previdenciária no Brasil. No entanto, o método de avaliação adotado, ainda que rigoroso, não permite examinar o efeito de alterações de políticas ainda não implementadas. Uma extensão deste trabalho é o desenvolvimento de um modelo estrutural de decisão contributiva capaz de prever a reação dos trabalhadores a alterações das regras previdenciárias. Naturalmente, o primeiro uso de um modelo como este seria verificar a sua capacidade de explicar a reação dos contribuintes voluntários diante da alteração de alíquota promovida pelo PSPS. Este e outros exercícios serão objeto de pesquisas futuras.

\section{Referências}

BERTRANOU, F. (2007) Informal Economy, Independent Workers and Social Security Coverage in Argentina, Chile and Uruguay, International Labour Office, mimeo.

BINET, G. e KULKE, U. (2006) Extension of social security to self-employed workers. OIT, mimeo.

BLUNDELL, R.; DIAS, M.C. (2000): Evaluation Methods for Non-Experimental Data, Fiscal Studies, vol. 21, n. 4 , p. 427-468.

BOSCH, M. e TORNEL, M. (2011). Welfare Policies and 'Informalization': the Effect of Popular Insurance on Semi-Formal Firms in Mexico. Anais do XXXVI Simpósio da Associação Espanhola de Economia.

BOSH, M. e MALONEY, W. (2005) Labor Market Dynamics in Developing Countries: Comparative Analysis using Continuous Time Processes, World Bank, mimeo.

Est. Econ., São Paulo, vol. 42, n.4, p. 639-669, out.-dez. 2012 
. Alternative Approaches to Evaluation in Empirical Microeconomics (2009) Journal of Human Resources, vol. 44, n. 3, p. 565-640.

CARD, D.; KRUEGER, A. B. (1994): Minimum wages and employment: a case study of the fast-food industry in New Jersey and Pennsylvania, American Economic Review, vol. 84, n. 4, p. 772-93.

(1995) Myth and measurement: the new economics of the minimum wage. New Jersey: Princeton University Press, 1995.

CORSEUIL, C. H.; CARNEIRO, F. G. (2001): Os impactos do salário mínimo sobre emprego e salários no Brasil: evidências a partir de dados longitudinais e séries temporais. IPEA, Texto para Discussão, n. 849.

DELGADO, G., QUERINO, A.C., CAMPOS, A., VAZ, F., RANGEL, L. e STIVALI, M. (2007): Avaliação do Simples: Implicações à Formalização Previdenciária, Texto para Discussão 1277, IPEA.

FAJNZYLBER, P. R. (2001): Minimum wage effects throughout the wage distribution: evidence from Brazil's formal and informal sectors. In: XXIX Encontro Nacional de Economia, Anais.

LEVY, S. (2006): "Social Policy, Productivity and Growth", background paper para o estudo regional: Beyond Survival: Protecting Households from Health Shocks in Latin America, World Bank.

LANZILOTTA (2009). El empleo por cuenta propia y la cobertura de seguridad social en Uruguay. In: OIT: Trabajadores Independientes y protección social en America Latina, Bertranou, F. (org.), Capítulo 2.

MALONEY, W. (1999) "Does informality imply segmentation in urban labor markets? Evidence from sectoral transitions in Mexico". World Bank Economic Review 13(2).

MEYER, B. D. (1995): Natural and quasi-experiments in economics, Journal of Business \& Economic Statistics, vol. 13, n.2, p. 151-61.

NERI, M. (1998): Os empresários da Rocinha. Rio de Janeiro, mimeo.

NERI, M. et al. (2007): Em busca de incentivos para atrair o trabalhador autônomo para a Previdência Social, Nova Economia, vol. 17,n. 3, p. 363-394.

NEUMARK, D.; CUNNINGHAM, W.; SIGA, L. (2006): The effects of the minimum wage in Brazil on the distribution of family incomes: 1996-2001, Journal of Development Economics, vol. 80, n. 1, p. $136-159$.

PUHANI, P. A. (2008): The treatment effect, the cross difference, and the interaction term in nonlinear difference-in-difference models. IZA Discussion Papers n. 3478, Institute for the Study of Labor, 2008.

ROFMAN, R.; LUCCHETTI, L. (2007): Pension Systems in Latin America: Concepts and Measurements of Coverage, Discussion Paper 616, World Bank.

RUPLEY B.B (1987): Stocastic Simulation, John Wiley \& Sons.

ROBERT C.P. Casella G. (2004): Monte Carlo Statistical Methods, Springer.

VALVERDE, F. (2009). La cobertura de los trabajadores independientes en la seguridad social de Costa Rica. In: OIT: Trabajadores Independientes y protección social en America Latina, Bertranou, F. (org.), Capítulo 6. 